\title{
PROBLEMAS E ANGÚSTIAS VIVENCIADOS POR PÓS-GRADUANDOS DE ENFERMAGEM: UMA ANÁLISE À LUZ DA EMPATIA
}

\author{
PROBLEMAS Y ANGUSTIAS VIVENCIADOS POR POST-GRADUANDOS DE \\ ENFERMERÍA: UN ANÁLISIS A LA LUZ DE LA EMPATIA
}

\author{
PROBLEMS AND ANGUISHES LIVED BY POST GRADUATES OF NURSING: AN \\ ANALYSIS TO THE LIGHT OF THE EMPATHY
}

\author{
Fernanda Leticia FRATES CAUDURO ${ }^{1}$ \\ Claudia PRADO ${ }^{2}$ \\ Rodrigo Francisco DE JESUS ${ }^{3}$
}

RESUMO: Objetivo: analisar propostas para lidar com problemas e angústia vivenciadas por pós-graduandos à luz dos hábitos da empatia. Método: pesquisa qualitativa, exploratória, realizada com 15 pós-graduandos em enfermagem de um Programa de Pós-Graduação em Enfermagem de uma Universidade Pública do sul do Brasil. A coleta de dados deu-se no mês de outubro de 2017, por meio de uma dinâmica a qual objetivo exercitar a prática da empatia. Resultados: A análise das falas procedeu mediante a Análise de Conteúdo e dela emergiram três categorias de análise: Problemas e angústias vivenciadas por pós-graduandos de enfermagem; Olhares, perspectivas e propostas e; Um olhar sobre os problemas e angústias dos pares: (in)compreensões, conflitos e debates. Considerações finais: predominaram queixas relacionadas a experiências vividas no âmbito da pós-graduação. As propostas caracterizaramse principalmente como conselhos e a empatia foi exercitada por poucos acadêmicos, assim considera-se necessário expandir o tema nos espaços acadêmicos.

PALAVRAS-CHAVE: Empatia. Educação de pós-graduação em enfermagem. Enfermagem.

RESUMEN: Objetivo: analizar propuestas para lidiar con problemas y angustia vivenciados por post graduados a la luz de los hábitos de la empatía. Método: investigación cualitativa, exploratoria, realizada con 15 post-graduandos en enfermería de un Programa de PostGraduación en Enfermería de una Universidad Pública del sur de Brasil. La recolección de datos se dio en el mes de octubre de 2017, por medio de una dinámica a la que el objetivo ejercitar la práctica de la empatía. Resultados: El análisis de las palabras procedió mediante el Análisis de Contenido y de ella surgieron tres categorías de análisis: Problemas y angustias vivenciados por post - graduandos de enfermería; Miradas, perspectivas y propuestas; Una mirada sobre los problemas y angustias de los pares: (des) entendimientos, conflictos y debates. Consideraciones finales: predominaron quejas relacionadas con las experiencias vividas en el ámbito del postgrado. Las propuestas se caracterizaron principalmente como

\footnotetext{
${ }^{1}$ Universidade Federal do Paraná (UFPR), Curitiba - PR - Brasil. Enfermeira do Departamento de Enfermagem. ORCID: <http://orcid.org/0000-0002-4731-9217>. E-mail: fernandacauduro@usp.br

${ }^{2}$ Universidade de São Paulo (USP), São Paulo - SP - Brasil. Professora Livre Docente do Departamento de Orientação Profissional (ENO). E-mail: claupra@usp.br

${ }^{3}$ Universidade do Grande Rio (UNIGRANRIO), Rio de Janeiro - RJ - Brasil. Coordenador do Curso de Enfermagem da Unigranrio. E-mail: roddejesus@gmail.com
} 
consejos y la empatía fue ejercida por pocos académicos, así que se considera necesario expandir el tema en los espacios académicos.

PALABRAS CLAVE: Empatia. Educación de Posgrado em Enfermería. Enfermería.

ABSTRACT: Objective: analyzing proposals to deal with problems and anguish experienced by graduate students in the light of the habits of empathy. Methods: a qualitative, exploratory research carried out with 15 graduate students in nursing of a Graduate Program in Nursing of a Public University in the south of Brazil. The data collection took place on October 2017, through a dynamic that aims to exercise the practice of empathy. Results: The analysis of the statements proceeded through Content Analysis and from it emerged three categories of analysis: Problems and anxieties experienced by nursing graduate students; Looks, perspectives and proposals and; A look at the problems and anxieties of peers: (mis)understandings, conflicts and debates. Final Considerations: predominated complaints related with lived experiences in the scope of Graduate Education. The proposals were mainly characterized as advice and empathy was exercised by few academics, so it is considered necessary to expand the theme in academic spaces.

KEYWORDS: Empathy. Nursing postgraduate education. Nursing.

\section{Introdução}

Nas últimas décadas o crescente acesso de enfermeiros a programas de mestrado e doutorado tem colaborado com a formação continuada desses profissionais e contribuído para a melhoria das práticas de cuidado (MACHADO et al., 2016). Quando inseridos nestes espaços de formação, os enfermeiros, agora estudantes, se deparam com responsabilidades, obrigações e atividades que exigem alto desempenho cognitivo (SOARES et al., 2010).

A pós-graduação strictu sensu implica na obrigatoriedade de publicação de material científico em periódicos nacionais e internacionais, bem como qualidade na produção da dissertação ou tese. Aliada a tais questões, o ambiente se caracteriza por relações verticalizadas entre docentes/orientadores e discentes/orientados, prevalecendo o ensino tradicional e baixa atenção a individualidade e subjetividade dos sujeitos (GUNNARSON; JONASSON; BILLHULT, 2013).

Na contramão a essa realidade, há o incentivo à adoção de modelos educacionais mais sensíveis e voltados à compreensão das necessidades dos alunos. Nesse contexto, a palavra empatia tem sido frequentemente utilizada como um meio para o alcance de relações positivas nos ambientes sociais, a incluir os acadêmicos (PONTES; GOMES, 2015). A empatia, termo derivado do alemão Uinfühlung, consiste na adoção de um comportamento em que se compreende os sentimentos e as atitudes de outros indivíduos de tal forma que as interações 
sociais se modificam e se estabelecem relações mais compreensivas e amigáveis (KRZNARIC, 2015).

Entre os cientistas que estudam este comportamento destaca-se Roman Krznaric, filósofo social australiano e historiador da cultura. Para ele, a partir da adoção dessa postura comportamental, é possível alcançar o estreitamento de relações humanas, melhoria do pensamento criativo e a minimização de pré-julgamentos e preconceitos (KRZNARIC, 2015).

Nesse contexto, verificam-se pontos de convergência para o debate acerca dos desafios enfrentados pelos alunos de pós-graduação e empatia. Diante desses argumentos, para a pesquisa que se apresenta, definiram-se os seguintes objetivos: identificar problemas e angústias vivenciados por mestrandos e doutorandos de enfermagem; e analisar as propostas para lidar com problemas e angústia vivenciados por pós-graduandos à luz da empatia.

\section{Método}

Pesquisa qualitativa, exploratória, recorte do projeto intitulado "Design Thinking: estratégia de fortalecimento para o uso de metodologias ativas no ensino superior" elaborado no âmbito da Escola de Enfermagem da Universidade de São Paulo. O cenário foi um programa de Pós-Graduação em Enfermagem (PPGEnf) de uma Universidade Pública situado em, Curitiba, Paraná, Brasil. A coleta de dados ocorreu em outubro de 2017, por meio de uma dinâmica, parte das estratégias de desenvolvimento de uma oficina pedagógica cujo foco era o Design Thinking, modelo mental que tem como um de seus pilares a empatia.

Os participantes foram selecionados de forma intencional. Para tal, foram convidados os pós-graduandos inscritos nas disciplinas de Estágio em Docência I e II, ofertada como disciplina obrigatória pelo PPGEnf. Definiram-se como critérios de inclusão ser pós-graduando de mestrado ou doutorado, estar matriculado e frequentando uma das disciplinas acima citadas, ter disponibilidade e aceitar ser participante da pesquisa por meio do preenchimento do Termo de Consentimento Livre e Esclarecido (TCLE) e Termo de Autorização do uso de imagem. Como critérios de exclusão e de descontinuidade foram considerados os participantes que demonstrassem interesse em retirar-se da pesquisa em qualquer uma de suas etapas.

Para a produção de dados realizou-se a dinâmica denominada "A troca de um segredo", a qual teve por objetivo exercitar a prática da empatia. Esta durou 123 minutos e ocorreu em três etapas. Na primeira, todos os presentes foram dispostos em semicírculo; a pesquisadora 
principal distribuiu uma filipeta de papel e caneta para cada participante e solicitou que nele fosse escrito um problema/angústia (não limitado a trabalho, família ou estudo).

Todas as anotações foram coletadas em um recipiente fechado, de cor escura, de modo que não pudesse ser visualizado seu interior. Na segunda etapa, cada participante apanhou uma filipeta aleatória e leu em voz baixa os escritos. Então, foi orientado que adotando uma postura empática fosse apresentada uma solução. Por fim, na última etapa, houve a resposta do emissor do problema/angústia ao receptor sobre a validade ou viabilidade da proposta.

As falas foram gravadas em áudio e vídeo e, após a finalização da oficina, foram transcritas na íntegra. Para a análise, adotou-se como referência a análise temática de conteúdo de Bardin (BARDIN, 2011). O sigilo e anonimato dos pós-graduandos foi garantido, sendo as falas codificadas pelas letras do alfabeto e atendidos os preceitos éticos conforme legislação vigente. A pesquisa foi aprovada pelo Comitê de Ética em Pesquisa (CEP) da Escola de Enfermagem da Universidade de São Paulo sob o registro CAAE: 68972217.0.0000.5392 e viabilidade favorável pelo CEP do Setor de Ciências da Saúde da UFPR.

\section{Resultados \\ Caracterização dos pós-graduandos}

Do total de 27 alunos matriculados nas disciplinas de Estágio em Docência I e II, 19 realizaram a inscrição via GoogleForms ${ }^{\circledR}$, sendo que 15 compareceram no local e data préestabelecidos. Destes, 53,3\% $(\mathrm{n}=8)$ eram mestrandos, três do sexo masculino e cinco do sexo feminino, com idades que variaram de 25 a 36 anos. Para o outro grupo, correspondente a 46,7\% $(n=7)$, participaram doutorandas com idade mínima de 28 a máxima de 38 anos. Do total de alunos, 12 possuíam algum vínculo empregatício, ao passo que três eram bolsistas pela Coordenação de Aperfeiçoamento de Pessoal de Nível Superior (CAPES) ou Conselho Nacional de Desenvolvimento Científico e Tecnológico (CNPq).

\section{Categorias da análise}

A dinâmica oportunizou a ocorrência de três movimentos: a) a expressão individual dos problemas/angústias vivenciados; b) o exercício da adoção de comportamento empático, por meio de proposta para a resolução do problema/angústia; c) a percepção do emissor do problema/angústia frente à proposta apresentada. Com isso foram identificadas as unidades de significado e elencadas as subcategorias da pesquisa, que resultaram em três categorias de análise. 


\section{Categoria 1 - Problemas e angústias vivenciados por pós-graduandos de enfermagem}

Os problemas/angústias relatados pelos pós-graduandos de enfermagem são apresentados tal como descritos nas filipetas. A partir deles emergiram oito subcategorias.

1-A gestão do tempo: "Administração do tempo"; "Falta de tempo para os compromissos assumidos"; "Terminar a dissertação em tempo". 2- A escrita científica: "A escrita da dissertação está estagnada"; "Finalizar o projeto de pesquisa e o artigo"; "Indisposição para a escrita”. 3- Dificuldade para conciliar família, trabalho e pós-graduação: "Conciliar meu trabalho e emprego que é em outra cidade com as exigências do mestrado". 4As escolhas profissionais: "Mudar de especialidade e ambiente de trabalho"; "Mudar de profissão e não consigo decidir que nova área quero atuar". 5-Desrespeito a valores $e$ prioridades de vida: "Meus valores e prioridades não serem respeitados pelos outros". 6Mudança de pensamento: "Implementar transformações de pensamento saudáveis". 7-A saúde de familiares: "Tenho uma filha com cefaléia contínua e com todos os exames "ok" e essa filha é bastante ansiosa"; "Saúde de meus avós"; "Meus avós residem em outra cidade e toda a família está se mobilizando para que os avós se mudem da residência e estejam mais perto dos filhos e netos". 8-Problemas domésticos: "Infiltração no banheiro".

Face aos apontamentos, cada participante foi convidado a refletir sobre o problema que tinha em mãos e a pensar, adotando uma postura empática, nas possíveis soluções.

\section{Categoria 2 - Olhares, perspectivas e propostas}

No segundo movimento da dinâmica as soluções foram explanadas pelos participantes que haviam lido o problema/angústia do colega. Deste momento, emergiram cinco subcategorias de análise e para ilustrá-las foram selecionadas falas representativas que expressam seu conteúdo.

\section{O planejamento e organização da rotina pessoal, no trabalho e na pós-graduação}

Diante da exibição de problemas relacionados ao planejamento das atividades acadêmicas e sua conciliação com a vida privada, as soluções tiveram como foco a busca por estratégias que possibilitassem ampliar o olhar dos pós-graduandos quanto às programações semanais e diárias. Neste sentido, as sugestões apontadas foram associadas ao uso de agendas, estabelecimento de metas e organização do tempo para si e para com outros. 
(...) semanalmente vou realizar um cronograma das atividades e dos planejamentos que eu preciso, é eu vou adquirir uma agenda, e vou estabelecer metas pra semana (...). (A)

\section{(Re)Definir prioridades pessoais, acadêmicas e profissionais}

Dentre as soluções apresentadas, foi apontado a necessidade da análise do estudante para o próprio contexto de vida, prioridades ou metas traças. Conforme ilustrado pela fala de $\mathrm{H}$, os problemas relatados pelo (a) emissor (a) do problema/angústia poderia ser oriundo de atitudes e valores estabelecidos contrários aos de seu convívio social. Ao passo que apresentou as soluções, os termos introspecção e empatia foram citados como consonantes.

Entender, porque provavelmente seja um contexto do trabalho, talvez, coletivo, o que eu acho é que tem que ser resolvido em primeiro lugar e o que para os outros não é tão urgente assim, eu acho que entender realmente assim, será que isso é prioridade, ou isso é da minha personalidade que eu quero né, impor acima das outras prioridades né, que o grupo elencou,e a outra coisa, é prioridade e valores (...)formação de valor é muito pessoal né. Eu acho que eu tentaria ter esse olhar de investigação. Sair do meu, ser mais empático. Por que as pessoas pensam de forma diferente da minha? Deve ter alguma razão, será que sou eu que to destoando tanto assim. Eu acho que é introspecção mesmo, conhecer o seu, se conhecer né, será que é prioridade, ou será que é eu to querendo colocar aquilo acima das outras pessoas? (H)

$\mathrm{Na}$ fala de $\mathrm{K}$, novamente atentamos para a proposta do uso de agendas para a organização da rotina, contudo ressalta do texto a expressão "assumiu também porque quis né", revelando o julgamento da participante sobre o problema a qual era responsável por analisar.

[...] mas assim, igual a (...) falou, acho praticamente a mesma coisa, eu falaria/reveria os compromissos assumidos, então assim, assumiu também porque quis né, então eu faria da seguinte forma (...) uma agenda eletrônica por que hoje a tecnologia ta aí pra isso (...) organizar por prioridades, por que compromisso é compromisso e eu vou ter que fazer, mas eu vou priorizar esses compromissos, tentar não sofrer por que como eu disse no começo da fala, fui eu que assumi, então vou ter que me organizar, ou ser humanamente, como diz, me fugiu a palavra, humilde, em falar infelizmente esse compromisso eu não tenho condição de assumir $(. .).(K)$

\section{A escolha profissional: avaliação de habilidades e interesses}

Nesta subcategoria as soluções foram destinadas aos problemas que indicavam conflitos quanto à escolha da carreira profissional. Em primeiro plano foi indicada a busca por formas de agregar valor à profissão, de modo que as habilidades e competências já formadas não fossem 
desprezadas. Nesse aspecto, a realização de um curso de mestrado foi notada como um caminho para a formação de nova habilidade na enfermagem, a docência, a qual poderia levar a satisfação profissional. Em segundo plano, a felicidade no campo profissional foi pautada, e no caso de completa insatisfação, sinalizaram como opção trilhar caminhos em outras áreas de atuação.

Então, eu penso em, é, planejar talvez pro ano que vem iniciar um novo curso, novas seleções de emprego, enfim, é não fica só é querendo e não tomar uma atitude. Vou procurar concurso, é alguma coisa que possa agregar a essa especialidade pra não precisar de repente perder tudo, né, pra tentar agregar, ou então se ta muito difícil iniciar do zero mesmo. (A)

(...) Se for realmente alguma coisa que perdura a muito tempo eu ia procurar outra coisa pra fazer porque não tem coisa mais infeliz do que fazer uma coisa que você não gosta pro resto da vida. Agora se você acha que é só uma questão do momento, né talvez seja a hora de você trabalhar e achar algo que você se identifica né, a gente ta dentro de um mestrado, mestrado profissional e acadêmico, mas é uma grande parte vai entrar na área da docência e é uma área de descoberta, de instigação, e eu acredito que seja muito prazerosa, ou as vezes não, você não quer trabalhar com docência, mas você quer trabalhar num campo específico. $(F)$

\section{O suporte familiar, de amigos e especialistas}

As soluções elencadas nesta subcategoria dizem respeito aos problemas relacionados à "Saúde de familiares" e "Problemas domésticos". No tocante aos problemas relativos à saúde, o olhar integral às necessidades dos entes queridos, busca por soluções compartilhadas e articuladas a outros membros da família ou especialistas, insurgiram como condutas a serem tomadas. A disponibilidade de tempo foi novamente citada para o enfrentamento dos problemas. Para vencer impasses do cotidiano doméstico, os amigos foram citados como importante fonte de apoio.

(...) levar num médico, escutar uma segunda opinião, (...) reservar mais tempo com os meus avós, até pela questão da idade, então eu sei que a gente tem muitos afazeres (...) então eu demandaria mais tempo com eles, levaria ao médico e se é difícil a questão do tempo eu também faria com os meus familiares um cronograma de quem vai ficar com eles um tempo pra que eles não precisassem ficar sozinhos. $(O)$

\section{Olhar empático: reciprocidade com sentimentos e angústias.}

Ao contrário dos demais estudantes, o participante $\mathrm{N}$ não apresentou solução direta ao problema o qual havia sorteado, mas exprimiu suas percepções quanto ao processo de formação 
durante o mestrado ou doutorado e os sentimentos gerados nesta etapa de transformação pessoal e profissional. Neste aspecto, são apresentados verbos que despontam para o suporte emocional e também motivacional, conferindo a aproximação ao comportamento empático esperado na dinâmica.

Eu passei por essa fase, então todo mundo sabe que a gente passa pelo mestrado e doutorado por várias etapas e depois você quando fala pro outro fala que não vai passa, mas ele passa também e todo mundo passa. Uns na pressão, outros não na pressão, uns com planejamento, outros sem, mas se a tua meta é aquela, então você vai alcançar né, independente do tempo, de repente você quer acabar o mestrado em dois anos e o doutorado em quatro, mas não é o tempo, contexto, a vida, a tua família ou o que acontece na tua volta faz com que você não termine, mas se a tua meta foi essa, se vai terminar um dia né, no tempo que for pra cada um aqui né. (N)

\section{Categoria 3 - Um olhar sobre os problemas e angústias dos pares: (in)compreensões, conflitos e debates}

No terceiro movimento da dinâmica os emissores dos problemas e angústias, descritos nas filipetas, expressaram se as soluções proferidas pelos colegas eram viáveis e pertinentes ao enfrentamento da situação. Nesta ação, foi oportunizado que os emissores explanassem com detalhe os problemas e que dialogassem com os demais participantes. Desta ação emergiram três subcategorias de análise, conforme apresentado a seguir:

\section{Problemas e angústias não compreendidos}

Ao analisar a proposta, os alunos perceberam incompreensão ao real problema vivido e, assim, as soluções apresentadas não se tornaram viáveis. Como meio para confortar o receptor e proponente da solução, indicaram a possibilidade de a escrita não ter sido adequada, o que, portanto, conferiu a incompreensão ao problema relatado.

Então, na verdade assim, é legal essa perspectiva, mas não era bem isso, acho que eu não consegui me expressar direito (...) (D)

$E$, então em partes por que, na verdade a interpretação tenha sido um pouquinho diferente né. É claro né, quando eu falo de valor claro é obviamente o que cada um tem para si como aquilo que acredita e eu acredito que a gente deva respeitar o outro, por que às vezes a gente tem nossos valores agredidos por que a pessoa desconsidera como sendo importante e daí partir do valor a gente estabelece prioridades também de vida né, então como ela também tá na questão das várias repercussões, é eu tenho o mestrado, eu 
tenho a família, eu tenho o trabalho, $e$ 'as vezes a pessoa que não tem todos esses elementos que eu tenho acaba desconsiderando isso e achando que eu não faço alguma coisa, ou que determinada atividade não é a prioridade numero um por que eu não quero ou por que eu não valorizo aquilo (...) (M)

\section{Conselhos e opiniões: soluções inadequadas}

Com a possibilidade de expressar a percepção frente às soluções apresentadas, os alunos se posicionaram e justificaram o motivo pelo qual as alternativas elencadas não seriam viáveis. Algumas estratégias enumeradas pelos colegas já haviam sido ponderadas pelos pósgraduandos, contudo não eficientes e oportunas ao conflito que estava sendo vivido.

Então, essa agenda aí não ta funcionando [risos], essa programação aí ta sendo feita, mas a demanda tá maior do que o tempo. Eu acho que eu tinha que diminuir as atividades. Mas valeu. (A)

A causa para a inviabilidade da solução também esteve associado à incompreensão quanto aos sentimentos experimentados pelo estudante. $\mathrm{Na}$ fala de $\mathrm{C}$, a angústia relacionada à necessidade de escrever o trabalho acadêmico e a constatação de que os prazos estavam a se estreitar refutaram a proposta enunciada pelo colega.

Essa solução é mais ou menos né, questão que eu acho que todo mundo passa por esses momentos né, você ta fluindo e de repente pára e parece que a gente não sai daquilo né, como ela falou que tem data pra acabar, acho que esse é o maior incentivo né, a qualificação ta chegando então tem que escrever né, e eu não tenho outra opção. $(C)$

Desconhecer em profundidade o problema vivido pelo colega, as questões pessoais e profissionais, e se pautar apenas pela descrição contida na filipeta possibilitou a incompreensão dos sentimentos vividos pelo emissor do problema. Na fala de $\mathrm{G}$, outras habilidades fora da área da saúde foram reveladas, porém a estabilidade financeira foi pontuada como causadora para se manter na enfermagem e com ela a angústia por não se permitir mudar de profissão e/ou área.

Na verdade tem várias coisas assim, é a minha dificuldade é escolher, é eu faço algumas outras coisas que não na enfermagem, não profissionalmente, mas assim, né. E assim o problema não é nem tudo, é quando você tem uma segurança financeira interessante, não que eu odeie o que eu faça, mas é uma coisa que não me completa assim, falta alguma coisa, falta algum tipo de habilidade assim. É que a profissão que eu queria talvez não me traz,.são demandas que afetam as outras demandas (...). É, na verdade acho que o problema, é a coragem mesmo, não sei como desenvolver, se alguém tiver uma sugestão? $(G)$ 
Ainda nesta linha, as soluções apresentadas aos problemas de saúde de entes queridos, não foram suficientes para vencer as barreiras explicitadas nas falas de O. Outras demandas que nas filipetas não haviam sido descritas foram pontuadas, como a logística de trabalho e distância entre cidades.

Então eu tenho, graças a Deus, eu tenho os quatro avós vivos (...) eu tenho muito afeto por eles e (...) passar mais tempo com eles tá um pouco difícil (...). A logística para a proposta ta difícil adotar. (O)

\section{“Sentir em": aproximação à empatia.}

Embora 11 propostas não tenham atendido às expectativas dos emissores dos problemas/angústias, quatro sugestões foram acolhidas. Para L, a maior fonte de angústia era produzida pelas tarefas e obrigações próprias do processo de formação na pós-graduação. As propostas para a resolução de tais problemas estavam vinculadas a reorganização das prioridades pessoais, laborais e ao suporte emocional.

Se viu, na verdade a gente acha que tem a resposta, que todo mundo sabe a resposta do seu problema, mas a gente não consegue colocar isso em prática né. Serviu sim a proposta. (...). Eu vou defender. Então assim, eu vou terminar, se não for em fevereiro vai ser um dia (...) a minha missão é terminar o mestrado, é isso que eu escolhi (...) é que o tempo não depende só da gente depende de pessoas né, a gente não faz nada sozinho e o tempo está passando e eu sei que o tempo está passando e minha parte eu estou fazendo, então assim, essa questão é complicada por que você é, você tem várias atribuições mas você não faz as coisas sozinho, você sempre depende do outro pra essa atividade, o que você tiver de fazendo, e o tempo você tem que ter com outro né (...). (L)

Por fim, a busca por apoio de amigos para lidar com problemas domésticos foi acatada pelo pós-graduando P. É pertinente destacar que, embora o problema descrito na filipeta fosse "infiltração", o estudante indicou em sua fala a negociação nas prioridades em sua rotina para tratar dos problemas residenciais e acadêmicos.

Eu vou explicar o meu problema. Acharam que eu ia escrever da minha dissertação? Esse problema de infiltração no banheiro (...) eu tava trabalhando, correndo com a apresentação da qualificação que é daqui um mês e ainda enfrentar esses problemas (...) mas serviu sim, vou falar com $\operatorname{amigos}(\ldots) .(P)$

\section{Discussão}


Os resultados obtidos na dinâmica apontam para a importância de serem compreendidos os problemas e conflitos vivenciados por estudantes de pós-graduação, uma vez que os mesmos impactam na qualidade das relações sociais, familiares e do ambiente acadêmico (GALDINO et al., 2016). Além disso, ficou evidente que, embora se tenha dado liberdade para que os participantes relatassem problemas de qualquer natureza, foram predominantes queixas relativas às atividades intrínsecas ao curso de mestrado ou doutorado.

Nesse sentido, uma das fontes para o desgaste cognitivo a que pós-graduandos enfrentam está na dificuldade para a redação científica. Ao adentrar na academia, o estudante é requisitado a produzir textos em linguagem específica os quais são submetidos ao processo de avaliação por pares, orientadores e bancas examinadoras (SIMÕES; JUCHUM, 2014). Nesta ação, a ansiedade pela confecção do material é fator de estresse, e possibilita a redução da capacidade na articulação de idéias e continuidade do trabalho (FARO, 2013). Neste sentido, a progressão na escrita da dissertação ou tese pode ser facilitada quando o estudante sente-se apoiado pelo orientador (SANTOS; PERRONE; DIAS, 2015).

Outra questão relevante repousa sobre a rotina intensa dos estudantes a qual os desafia a conciliar o mestrado/doutorado a manutenção das relações sociais, atividades de lazer e descanso. A cobrança para dedicação à família por vezes é demandada pelos pais, cônjuges e filhos, por não compreenderem as novas rotinas e o distanciamento, ainda que temporário, do convívio social (FREITAG, 2016). Em contrapartida, a motivação para vencer as tarefas acadêmicas proveniente de familiares e colegas próximos é essencial para o pós-graduando e o auxiliam no percurso acadêmico (SANTOS; PERRONE; DIAS, 2015).

Nesse aspecto, os colegas da academia são uma importante fonte de apoio no enfrentamento das situações vividas na pós-graduação, pois oportunizam troca de informações e experiências (GARDNER, 2010); já os professores munidos de empatia podem facilitar o processo de aprendizado (PONTES; GOMES, 2015) e propiciar o sucesso da dissertação/tese e da produção acadêmica (SANTOS; PERRONE; DIAS, 2015).

No tocante a análise dos movimentos oportunizados pela dinâmica à luz da empatia, tomou-se como referência os pressupostos de Roman Krznaric que propõe a aquisição de seis hábitos para o desenvolvimento e prática do referido comportamento: reconhecer a empatia como habilidade a ser desenvolvida; reconhecer a humanidade, individualidade e perspectivas dos indivíduos; buscar experiências que promovam hábitos de empatia; praticar a conversação; inspirar-se por meio da arte, literatura e mídias; e expandir a empatia - de comportamentos individuais para coletivos (KRZNARIC, 2015). Na análise das categorias e subcategorias, foi possível estabelecer relações com o primeiro, segundo e quarto hábito. 
Sobre o primeiro, a empatia pode ser desenvolvida e com isso é possível que todos os indivíduos a expandam ao terem atenção aos sentimentos e experiências de outras pessoas (KRZNARIC, 2015). No grupo pesquisado, a necessidade do desenvolvimento dessa habilidade é revelada pela resposta de $\mathrm{M}$ a $\mathrm{H}$. Ao passo que foi apresentada como proposta a revisão das prioridades de vida e adoção da empatia, a pós-graduanda $\mathrm{M}$ a invalidou, ao afirmar que vivencia o desrespeito as suas prioridades e valores no contexto do mestrado/doutorado.

$\mathrm{Na}$ fala de H, destaca-se o uso das expressões "introspecção", "conhecer o seu" e "se conhecer" utilizados como posturas convergentes a empatia. Sobre isso, Krznaric afirmar que no último século vivemos a Era da Introspecção, movimento que propagou o autoconhecimento como um recurso para a auto-realização, satisfação e felicidade. Assim, esta Era fomentou a adoção de comportamentos egoístas e hiper-valorização das próprias necessidades em detrimento dos outros sujeitos. Para vencer esta lacuna, o filósofo propõe a Era da Outrospecção, ou seja, a descoberta de quem somos e como devemos viver ao se explorar vidas e perspectivas de outros indivíduos (KRZNARIC, 2015).

A evidência na prática de comportamentos empáticos ainda se constitui como desafio, pois, geralmente, este atributo é compreendido como qualidade pessoal. Deste modo, meios para promover a capacitação, de forma sistemática, da empatia como habilidade de interação humana, se configura como desafio nos diversos espaços sociais (KESTEMBERG, 2013).

Em direção ao segundo hábito, a fala que segue desperta atenção, pois a estudante que realiza a proposta de como lidar com o problema/ angústia, embora busque propor soluções, julga o colega pelas suas escolhas, atitude esta insinuada pela expressão "assumiu também por que quis né”. Na busca pelo desenvolvimento de habilidades empáticas, volta-se para reconhecimento da humanidade, individualidade e perspectivas alheias.

O propósito para a invisibilidade destes comportamentos na sociedade encontra-se em barreiras sócio-políticas traduzidas em preconceito, autoridade, distância e negação. Ademais, configura-se como desafio ao empata compreender que não podemos impor nossos códigos morais e interpretações de mundo ao outro, respeitando as subjetividades e singularidades 5 . Complementar a esta idéia, autores indicam as competências observar, ouvir, compreender e comunicar-se como subsídios primordiais da empatia (PONTES; GOMES, 2015; FALCONE et al., 2008)

Em contrapartida, demonstrando proximidade a este hábito, o estudante $\mathrm{K}$ indicou afinidade ao plano para ele proposto, conforme revelado em sua fala. O fato de o diálogo ter sido estabelecido nas últimas etapas da dinâmica conferiu caminho para o exercício do quarto hábito da empatia, o incentivo a conversação. Com o diálogo é possível compreender a vida 
emocional e penetrar nos sentimentos, emoções, ideias, medos e tantos outros sentimentos particulares. Em geral, pessoas empáticas, ao estabelecerem uma conversa, são corajosas e curiosas, buscam sentido nas palavras e histórias relatadas, estão abertos a ouvir, são autênticos e verdadeiros em palavras e gestos, demonstram preocupação pelo outro e são criativos para explorar e reconhecer as emoções, sentimentos e histórias relatadas (PONTES; GOMES, 2015).

Além da conversação, o primeiro e segundo hábito é identificado na fala de K. O desafio para adquirir este hábito está em repensar a maneira como os diálogos são conduzidos de forma que seja possível apreender os pensamentos de outros, as visões de mundo e estabelecer, ou criar, vínculos emocionais a elas. Neste debate, surgem equívocos, pois a empatia e compaixão por vezes são compreendidas como sinônimo, o que se torna um fator de impedimento para seu aprimoramento individual e social. A compaixão está relacionada a penalização, sentimentos de piedade e misericórdia ao passo que na empatia há uma conexão ao sentimento do outro, um "sentir em" (KRZNARIC, 2015).

Para além dos hábitos enumerados pelo filósofo, a empatia como competência individual tem sido desenvolvida nos espaços acadêmicos, com o tema transposto para o contexto da formação em saúde. Para tal, docentes valem-se de atividades problematizadas, simulações, uso de tecnologias digitais, reflexão escrita e programas de treinamento (KESTEMBERG, 2013; SARMIENTO et al., 2017).

Ademais, no contexto da pós-graduação, inventários que avaliam comportamentos empáticos (KESTEMBERG, 2013; FALCONE et al., 2008) podem ser utilizados como recurso para a obtenção de diagnósticos situacionais e, a partir das respostas, repensadas as relações entre pós-graduandos, docentes e orientadores.

\section{Considerações finais}

A pesquisa possibilitou a identificação dos principais problemas e angústias vivenciados por um grupo de mestrandos e doutorandos em enfermagem. Embora pudessem expressar sentimentos relacionados a trabalho, família ou estudo, houve predomínio de queixas associadas às experiências no âmbito da pós-graduação. Nesse sentido, foram reafirmadas e corroboradas à literatura, questões relativas ao relacionamento entre pares, orientadores e professores, vida privada, além da alta demanda de atividades corriqueiras pertencentes ao processo de formação do mestre ou doutor em enfermagem.

O comportamento empático foi experimentado por poucos pós-graduandos ao colocarem-se no lugar de seus colegas e apresentarem alternativas para o enfretamento dos 
problemas explicitados. Nas duas últimas etapas da dinâmica, foram preponderantes atitudes com foco em conselhos, o que demonstrou a dificuldade na adesão à postura empática. Ao serem analisadas as falas à luz dos hábitos da empatia de Krznarik, percebeu-se a relevância de expandir este assunto, e por sua vez o desenvolvimento de habilidades empáticas no contexto acadêmico.

Por se tratar de um grupo de enfermeiros docentes em formação reitera-se a importância do desenvolvimento de habilidades empáticas uma vez que, como formadores, irão se deparar com alunos/profissionais com problemas, dificuldades e angústias. Assim, é esperado que em uma posição horizontal não repliquem o modelo ao qual estão sendo submetidos e transformem estigmas associados à formação de mestres e doutores.

A limitação da pesquisa está na impossibilidade de generalizar os resultados obtidos uma vez que a abordagem foi qualitativa e houve intencionalidade quanto ao grupo, tempo e contexto estudado. Não obstante, mediante o baixo aporte teórico, é preciso ampliar investigações que relacionem a empatia com a pós-graduação scrictu sensu e o fomento de propostas que permita seu desenvolvimento como competência humana necessária nas relações sociais.

\section{REFERÊNCIAS}

BARDIN, Laurence. Análise de Conteúdo. Lisboa: Ed.70; 2011.

FARO, André. Estresse e estressores na pós-graduação: estudo com mestrandos e doutorandos no Brasil. Psicologia: Teoria e Pesquisa. v. 29, n.1, p.51-60, 2013. DOI: http://dx.doi.org/10.1590/S0102-37722013000100007

FALCONE, Eliane Mary Oliveira, et al. Inventário de empatia (IE): desenvolvimento e validação de uma medida brasileira. Rev Aval Psicológica. v. 7, n. 3, p. 321-334, 2008.

FREITAG, Vera Lucia, et al. O cotidiano de pós-graduandos stricto sensu em enfermagem de uma Universidade Federal. Revista Contexto e Saúde. v. 16, n. 30, p. 3-13, 2016. DOI: https://doi.org/10.21527/2176-7114.2016.30.3-13.

GALDINO, Maria José Quina, et al. Mestrado em enfermagem: sentimentos vivenciados por estudantes. Rev. Enferm. UFPE on line, v. 10, n.3, p. 501-507, 2016. DOI: 10.5205/reuol.8557-74661-1-SM1002201616.

GARDNER, Susan Kristine. Contrasting the socialization experiences of doctoral students in high -and low- completing departments: a qualitative analysis of disciplinary contexts at one institution. J High Educ. n. 1, p. 61-81, 2010. DOI: https://doi.org/10.1080/00221546.2010.11778970. 
GUNNARSSON, Ronny; JONASSON, Grethe; BILLHULT, Annika. The experience of disagreement between students and supervisors in $\mathrm{PhD}$ education: a qualitative study. BMC Medical Education. v.13, n.134, p.1-8, 2013.

KESTEMBERG, Celia Caldeira Fonseca. A habilidade empática é socialmente aprendida: um estudo experimental com graduandos de enfermagem. Rev. enferm. UERJ, v. 21, n. 4, p. 427-433, 2013.

KRZNARIC, Roman. O poder da empatia: a arte de se colocar no lugar do outro para transformar o mundo. Tradução Maria Luiza X. de A. Borges. Rio de Janeiro: Ed Zahar, 2015.

MACHADO, Maria Helena, et al. Aspectos gerais da formação da enfermagem: o perfil da formação dos enfermeiros, técnicos e auxiliares. Enferm. Foco, v. 6, n. 2/4, p. 15-34, 2016.

PONTES, Leticia; GOMES, Cleomar Ferreira. A habilidade empática do professor na dinamização da sua prática pedagógica. Cadernos de Pesquisa: Pensamento

Educacional, v. 10, n. 25, p. 175-193, 2015.

SANTOS, Analise Schaurich dos; PERRONE, Cláudia Maria; DIAS, Ana Cristina Garcia. Adaptação à pós-graduação stricto sensu: uma revisão sistemática de literatura. Psico-USF, v. 20, n.1, p.141-152, 2015.

SARMIENTO, Pilar Bas, et al. Efficacy of empathy training in nursing students: a quaseexperimental study. Nurse Education Today, v. 59, n. 1, p. 59-65, 2017.

DOI:10.1016/j.nedt.2017.08.012.

SIMÕES, Luciene Juliano; JUCHUM, Maristela. A escrita na universidade: uma reflexão com base no que os alunos dizem em seus textos. Horizontes de Linguística Aplicada, n. 13, p. 107-129, 2014.

SOARES, Rayssa Soares; TRIGUEIRO, Renata; ALMEIDA, Tatiane de; OLIVEIRA, José Arimatés. A pós-graduação e a síndrome de Burnout: um estudo com alunos de mestrado em administração. Revista Pensamento Contemporâneo em Administração, v. 4, n. 3, p. 12$21,2010$.

\section{Como referenciar este artigo}

FRATES CAUDURO, Fernanda Leticia; PRADO, Claudia; DE JESUS, Rodrigo Francisco. Problemas e angústias vivenciados por pós-graduandos de enfermagem: uma análise à luz da empatia. Temas em Educ. e Saúde, Araraquara, v. 15, n. 1, p. 3-17, jan./jul., 2019. e-ISSN 2526-3471. ISSN 1517-7947. DOI: 10.26673/tes.v15i1.11938

Submetido em: 03/12/2018

Aprovado em: 03/03/2019 